\title{
IDENTIFIKASI IBU BERSALIN PEROKOK PASIF TERHADAP KEJADIAN PLACENTA PREVIA DI RUMAH SAKIT WILAYAH KABUPATEN KENDAL
}

\author{
Titi Mursiti ${ }^{1}$, Tri Nurhidayati ${ }^{2}$ \\ 1,2UPP Kampus Kendal Poltekkes Kemenkes Semarang
}

\begin{abstract}
The incidence of placenta previa has doubled in women who smoke. This happens because the carbon dioxide inhaled can cause placental hypertrophy, thereby affecting the development of the placenta. The purpose of this study was to identify maternal passive smokers against the incidence of placenta previa. This type of research is descriptive survey, which is a method carried out with the aim of describing a situation objectively. Method of sampling with accidental sampling as many as 20 respondents who experienced placenta previa in November 2107-May 2018. From the results of the study it can be concluded that mothers with placenta previa passive smokers as many as 15 people (75\%) and mothers giving placenta previa non-passive smokers as many as 5 people (25\%) in conclusion, there are 15 maternal mothers with placenta previa passive smokers (75\%) in Kendal District Hospital. It is recommended for the community especially pregnant women if their husbands, family members or the surrounding community who smoke, should avoid or wear masks so that they are not exposed to cigarette smoke and do not interfere with pregnancy in childbirth later.
\end{abstract}

Keywords: Placenta Previa, Passive Smokers. 


\section{PENDAHULUAN}

Masalah kesehatan ibu masih jauh dari keadaan yang diharapkan. Survei Demografi dan Kesehatan Indonesia (SDKI) yang dihelat lima tahun sekali sejak tahun 1987, ditujukan untuk mengumpulkan data mengenai kependudukan, keluarga berencana, dan kesehatan.

Tahun 2012 AKI mencapai 359 per 100 ribu kelahiran hidup atau meningkat 57 persen bila dibandingkan dengan tahun 2007, yang hanya sebesar 228 per 100 ribu kelahiran hidup. Hal ini masih jauh dari target MDGs 2015 yaitu 108 per 100 ribu kelahiran hidup. Jumlah angka kematian ibu (AKI) di JawaTengah tahun 2013 yaitu 29 per 100 ribu kelahiran hidup. Pada akhir tahun 2015 provinsi Jawa Tengah mencanangkan target Angka Kematian Ibu sebesar 70 per 100.000 kelahiran hidup. (http://www.lensaindonesia.com/)

Latar belakang kematian maternal adalah perdarahan obstetrik (24,8\%), infeksi $(14,9 \%)$, eklamsia $(12,9 \%)$, dan sebabsebab langsung lain (7,9\%). Perdarahan obstetrik yang sampai menyebabkan kematian maternal terdiri atas solusio plasenta (19\%), plasenta previa (7\%), plasenta akreta/inkreta dan perkreta (6\%) dan atonia uteri (15\%). (Prawirohardjo, 2009, h; 493)

Perdarahan obstetrik yang terjadi pada kehamilan trimester ketiga dan yang terjadi setelah anak atau plasenta lahir pada umumnya adalah perdarahan yang berat, dan jika tidak mendapat penanganan yang cepat bisa mendatangkan syok yang fatal. Salah satu sebabnya adalah plasenta previa (Sarwono, 2009, h; 495)

Plasenta previa adalah plasenta yang berimplantasi pada segmen bawah rahim dan menutupi sebagian atau ostium uteri internum. Angka kejadian plasenta previa adalah $0,4-0,6 \%$ dari keseluruhan persalinan (Sarwono, 2010, h; 162)

Kejadian plasenta previa meningkat 2 kali lipat pada wanita yang merokok. Hal tersebut terjadi karena karbondioksida yang terhisap mampu menyebabkan hipertrofi (pembesaran) dari plasenta serta menyebabkan peradangan dan berkurangnya vaskularisasi (perdarahan) plasenta sehingga mempengaruhi perkembangan dari plasenta (William, 2006, h; 699)

Studi pendahuluan di RS Wilayah Kabupaten Kendal yaitu RSUD Dr. $\mathrm{H}$. Soewondo Kendal dan RSI Muhammadiyah Kendal, didapatkan jumlah ibu bersalin di RSUD Dr. $\mathrm{H}$. Soewondo Kendal tahun 2013 sebanyak 3350 orang. Ibu bersalin dengan plasenta previa 44 orang $(1,3 \%)$.

Ibu bersalin dengan plasenta previa 18 orang (1.2\%). RSI Muhammadiyah Kendal tahun 2013 juga tidak terdapat Angka Kematian lbu (AKI) yang disebabkan perdarahan karena plasenta previa maupun penyakit komplikasi lainnya.

Di RSUD Dr. H. Soewondo Kendal pada tahun 2015 tidak terdapat Angka Kematian Ibu (AKI) yang disebabkan perdarahan 
karena plasenta previa maupun penyakit komplikasi lainnya. Sedangkan di RSI Muhammadiyah Kendal pada tahun 2017 jumlah ibu bersalin sebanyak 145 orang. Studi kepustakaan menerangkan bahwa salah satu faktor resiko yang menyebabkan meningkatnya seorang ibu atau wanita hamil akan mengalami plasenta previa yaitu disebabkan oleh merokok. Maka dari itu peneliti tertarik untuk melakukan penelitian tentang identifikasi ibu bersalin perokok pasif terhadap kejadian plasenta previa di RS Wilayah Kabupaten Kendal. Tujuan umum untuk mengidentifikasi ibu bersalin perokok pasif terhadap kejadian plasenta previa di RS Wilayah Kabupaten Kendal.

\section{METODOLOGI PENELITIAN}

Jenis penelitian yang digunakan dalam penelitian ini adalah diskriptif dengan pendekatan survei, yaitu suatu metode penelitian yang dilakukan dengan tujuan untuk membuat gambaran atau deskripsi tentang suatu keadaan secara objektif. Variabel independen dalam penelitian ini adalah ibu bersalin perokok pasif. Variabel dependen merupakan variabel yang dipengaruhi. Variabel dependen dalam penelitian ini adalah plasenta previa.

Populasi adalah wilayah generalisasi yang terdiri atas obyek/subyek yang mempunyai kualitas dan karakteristik tertentu yang ditetapkan oleh peneliti untuk dipelajari dan kemudian ditarik kesimpulannya (Sugiyono, 2011; h. 61). Populasinya adalah semua ibu bersalin dengan plasenta previa di RSUD Dr. Soewondo Kendal dan RSI Muhammadiyah pada bulan November 2017 - Mei 2018. Sampel adalah bagian dari jumlah dan karakteristik yang dimiliki oleh populasi (Sugiyono, 2011; h. 62). Sampel dalam penelitian ini adalah ibu bersalin dengan plasenta previa di RSUD Dr. H. Soewondo Kendal dan RSI Muhammadiyah Kendal pada bulan November 2017 - Mei 2018. Kriteria inklusi adalah kriteria atau ciri-ciri yang perlu dipenuhi oleh setiap anggota populasi yang dapat diambil sebagai sampel (Notoatmodjo, 2012; h. 130). Kriteria inklusi dalam penelitian ini adalah lbu bersalin dengan plasenta previa di RSUD Dr. H. Soewondo Kendal dan RSI Muhammadiyah Kendal pada bulan November 2017 - Mei 2018. Kriteria eksklusi adalah ciri - ciri anggota populasi yang tidak dapat diambil sebagai sampel (Notoatmodjo, 2012; h. 130). Kriteria ekslusi meliputi ibu bersalin dengan plasenta previa yang tidak ada di tempat saat penelitian (pindah) sebanyak 3 orang dan ibu bersalin plasenta previa yang alamatnya kurang jelas 2 orang. Teknik pengambilan sampel kasus pada penelitian ini menggunakan teknik Accidental sampling yaitu dengan mengambil kasus atau responden yang kebetulan ada atau tersedia di suatu tempat sesuai dengan konteks penelitian.(Notoatmodjo, 2012; h. 125). Instrumen penelitian adalah alat-alat yang akan digunakan untuk pengumpulan data (Notoatmodjo, 2012; h. 87). Dalam 
penelitian ini alat ukur yang digunakan yaitu kuesioner (wawancara) dan observasi rekam medik. Cara penggumpulan data dengan data primer dan sekunder. Data primer merupakan materi atau kumpulan fakta yang dikumpulkan sendiri oleh peneliti saat penelitian berlangsung. Data sekunder merupakan data yang diperoleh peneliti dari pihak lain.

Langkah-langkah pengolahan data yaitu melalui Editing dan Coding. (Hidayat, 2007; h. 121-122)

Data entry adalah memasukkan data yang telah dikumpulkan ke dalam master tabel atau database komputer Analisis Data menggunakan analisa univariate. Analisis univariate bertujuan untuk menjelaskan atau mendiskripsikan karakteristik setiap variabel penelitian (Notoatmodjo, 2011; h. 182). Etika Penelitian yang dilakukan adalah Informed Consent (lembar persetujuan), Anonimity (tanpa nama) dan Kerahasiaan (confidentiality).

\section{HASIL PENELITIAN DAN BAHASAN}

Tabel . 1 Distribusi Frekuensi Plasenta Previa Berdasarkan Perokok Pasif di RSUD Dr. H. Soewondo Kendal dan RSI Muhammadiyah Kendal bulan November 2017 - Mei 2018

\begin{tabular}{lll}
\hline $\begin{array}{l}\text { Perokok } \\
\text { Pasif }\end{array}$ & Frekuensi (f) & Persentase (\%) \\
\hline Ya & 15 & $75 \%$ \\
Tidak & 5 & $25 \%$ \\
\hline Total & 20 & 100.0 \\
\hline Berdasarkan tabel 1 & dapat diketahui \\
bahwa dari 20 responden ibu bersalin
\end{tabular}

plasenta previa yang perokok pasif sebanyak 15 orang (75\%). Sedangkan ibu bersalin plasenta previa yang tidak perokok pasif sebanyak 5 orang (25\%).

Tabel 2 Distribusi Frekuensi Persalinan Spontan Berdasarkan Perokok Pasif di RSUD Dr. H. Soewondo Kendal

RSI Muhammadiyah Kendal bulan November 2017 - Mei 2018

\begin{tabular}{lll}
\hline $\begin{array}{l}\text { Persalinan } \\
\text { Spontan }\end{array}$ & Frekuensi (f) & $\begin{array}{l}\text { Persentase } \\
(\%)\end{array}$ \\
\hline Ya & 3 & $15 \%$ \\
Tidak & 17 & $85 \%$ \\
\hline Total & 20 & 100.0 \\
\hline
\end{tabular}

Berdasarkan tabel 2 dapat diketahui bahwa dari 20 responden ibu bersalin spontan yang perokok pasif sebanyak 3 orang (15\%). Sedangkan ibu bersalin spontan yang tidak perokok pasif sebanyak 17 orang (85\%).

Tabel. 3 Distribusi Frekuensi Hubungan Ibu Bersalin Perokok Pasif Dengan Kejadian Plasenta Previa Di RSUD Dr. H. Soewondo Kendal dan RSI Muhammadiyah Kendal bulan November 2017 - Mei 2018

\begin{tabular}{|c|c|c|c|c|}
\hline \multirow{2}{*}{$\begin{array}{l}\text { Jenis } \\
\text { Persalinan }\end{array}$} & \multicolumn{2}{|c|}{ Perokok Pasif } & \multirow{2}{*}{ Total } & \multirow{2}{*}{$\begin{array}{c}\rho \\
\text { Value }\end{array}$} \\
\hline & $\mathrm{Ya}$ & Tidak & & \\
\hline \multicolumn{5}{|l|}{ Plasenta } \\
\hline Previa & $15(75.0 \%)$ & $5(25.0 \%)$ & $20(100.0 \%)$ & 0.001 \\
\hline Spontan & $3(15.0 \%)$ & $17(85.0 \%)$ & $20(100.0 \%)$ & \\
\hline Total & $18(45.0 \%)$ & $22(55.0 \%)$ & $40(100.0 \%)$ & \\
\hline
\end{tabular}

Berdasarkan tabel. 3 dapat diketahui bahwa ibu bersalin plasenta previa perokok pasif sebanyak 15 orang (75\%) dan ibu bersalin plasenta previa tidak perokok pasif sebanyak 5 orang (25\%). Sedangkan ibu bersalin spontan yang perokok pasif sebanyak 3 orang (15\%) dan 
ibu bersalin spontan yang tidak perokok pasif sebanyak 17 orang (85\%)

Berdasarkan penelitian yang dilakukan pada 20 respoden di RSUD Kendal dan RSI Muhammadiyah Kendal dapat diketahui bahwa ibu bersalin dengan plasenta previa perokok pasif sebanyak 15 orang $(75 \%)$ dan ibu bersalin plasenta previa tidak perokok pasif sebanyak 5 orang (25\%).

Plasenta previa adalah keadaan dimana plasenta berimplantasi pada segmen bawah rahim sehingga menutupi sebagian atau seluruh pembukaan jalan lahir (Mochtar, 1996; h, 269).

Rokok merupakan salah satu zat adiktif, yang bila digunakan dapat mengakibatkan bahaya kesehatan bagi individu dan masyarakat. Perokok pasif adalah seseorang yang tidak memiliki kebiasaan merokok, namun terpaksa harus mengisap asap rokok yang dihembuskan oleh orang lain yang kebetulan ada di dekatnya.

Latar belakang kematian maternal adalah perdarahan obstetrik, perdarahan obstetrik yang terjadi pada kehamilan trimester ketiga dan yang terjadi setelah anak atau plasenta lahir pada umumnya adalah perdarahan yang berat, dan jika tidak mendapat penanganan yang cepat bisa mendatangkan syok yang fatal. Salah satu sebabnya adalah plasenta previa (Sawono, 2009; h, 495). Kejadian plasenta previa meningkat 2 kali lipat pada wanita yang merokok. Hal tersebut terjadi karena karbondioksida yang terhisap mampu menyebabkan hipertrofi (pembesaran) dari plasenta serta menyebabkan peradangan dan berkurangnya vaskularisasi (perdarahan) plasenta sehingga mempengaruhi perkembangan dari plasenta, sehingga merangsang pertumbuhan plasenta yang besar dan mengakibatkan plasenta previa (William. 2005;h.699)

Hasil penelitian menunjukkan adanya kesesuaian dengan teori, dimana faktor penyebab terjadinya plasenta previa salah satunya yaitu merokok. Adapun kandungan dalam rokok terdapat nikoton dan karbon monoksida. Jika ibu hamil menghirup asap rokok, oksigen dan nutrisi dari ibu untuk bayi yang dikandung akan berkurang karena terjadi penyempitan pembuluh darah dan mengakibatkan pertumbuhan plasenta akan suplai oksigen dan nutrisi ke janin berkurang. Oleh karena itu akan merangsang plasenta untuk mencari oksigen dan nutrisi yang lebih banyak di segmen bawah Rahim.

Pada ibu bersalin yang mengalami plasenta previa sebagian besar disebabkan oleh suami dan anggota keluarganya merokok. Ibu hamil yang setiap harinya tinggal serumah dengan suami dan anggota keluarga yang merokok akan menghirup asap rokok dari si perokok tersebut dan ibu hamil sebagai perokok pasif

\section{KESIMPULAN}


Dari hasil penelitian Identifikasi Ibu Bersalin Perokok Pasif dengan Kejadian Plasenta Previa Di RS Wilayah Kabupaten Kendal dapat disimpulkan bahwa ibu bersalin dengan plasenta previa perokok pasif sebanyak 15 orang $(75 \%)$ dan ibu bersalin plasenta previa tidak perokok pasif sebanyak 5 orang (25\%).

Saran dalam penelitian ini adalah diharapkan untuk ibu hamil menghindar dari orang yang merokok atau menggunakan masker supaya tidak terkena paparan asap rokok dan tidak mengganggu kehamilan dalam persalinannya nanti.

\section{DAFTAR PUSTAKA}

1. Adhiatma, Gunawan. Merokok vs Kehamilan. 2012. Web http://www.mommeworld.com/post/view /is/merokok-vs-kehamilan/

2. Anonymous. Bagaimana Merokok Mempengaruhi Kehamilan. 2011. Web http://www.artikelpria.com/2011/03/14/b agaimana-merokok-mempengaruhikehamilan.html

3. Candra,Budiman. Metodiologi penelitian Kesehatan. Jakarta: EGC,2008

4. Cuningham F. Gary, Norman F. Gant, Kenneth J. leveno, Larry C. Hauth, Katharine D. Wenstrom. Obstetri Williams. Jakarta : EGC,2006

5. Danim, Sudarman dan Darwis. Metode Penelitian Kebidanan. Jakarta: EGC,2003

6. Elizabet Aula, Lisa. Stop Merokok. Jogjakarta: Gara IImu,2010

7. Fraser, Diane M. Buku Ajar Bidan Myles. Jakarta: EGC,2009

8. Hidayat A Aziz alimul. Metode penelitian Kebidanan Teknik Analisis Data. Jakarta: Salemba medika,2011
9. Manuaba IBG. IImu Kebidanan, Penyakit Kandungan dan Kb. Jakarta: EGC, 1998

10. Maggie Evans, Baverley Marsh. Sunan Battersby, Angela Walker. Kebidanan Oxford. Jakarta: EGC,2011

11. Maryunani Anik, Yulianingsih. Asuhan Kebidanan Kegawatdaruratan dalam Kebidanan. Jakarta: CV Trans Info Media,2009

12. Mochtar Rustam. Sinopsis Obstetri. Jakarta: EGC,1998

13. Notoadmodjo Soekidjo. Metodologi Penelitian Kesehatan. Jakarta; Rineka Cipta,2012

14. Prawiroharjo Sarwono. Buku acuan Nasional pelayanan kesehatan Maternal dan Neonatal. Jakarta: Yayasan Bina Pustaka,2010

15. Prawirohardjo Sarwono. IImu kebidanan. Jakarta: PT Bina Pustaka,2009

16. Profil Kesehatan Kabupaten Kendal

17. Ruslan, Kadir. Catatan menjelang 2014: Angka Kematian Ibu Meningkat. 2014.

Web http://kesehatan.kompasiana.com/ ibudan-anak/2013/10/03 /catatan menjelang 2014 angka-kematian-ibumeningkat.html

18. Sugiyono. Statistika Untuk Penelitian. Bandung: Alfabeta,2011

19. Varney Helen, Jan M.Kriebs, Crolyn L.gegor. Buku Ajar Asuhan Kebidanan. Jakarta: EGC,2008 